\title{
Labor entre culturas e indagación teológica
}

\section{The work between cultures and theological research Trabalho entre culturas e investigação teológica}

\author{
Mag. Diego Irarrazaval ${ }^{1}$
}

Recibido: 29/05/2016 · Aceptado: 06/09/2016

\begin{abstract}
Resumen
La interacción entre personas de diferentes culturas -afectadas por factores globales y por el cambio de época- incentiva nuevos modos de pensar en América Latina. Al dialogar con voces filosóficas (y en especial con Raúl Fornet-Betancourt), uno ve modos de entender y transformar el mundo; este diálogo suscita interrogantes teológicos. Luego de anotar elementos contextuales, considero unos ejes del pensamiento intercultural, y gracias a ellos voy delineando cinco tipos de interrogantes. A mi parecer, las ciencias no explican problemas que sean resueltos por parámetros cristianos. Más bien, un polílogo fecundo y simétrico permite dar pasos hacia una humanización liberadora. En este caminar son encaradas preguntas que reconfiguran el imaginario cristiano.
\end{abstract}

Palabras claves: Lo intercultural e interreligioso - Fornet Betancourt - Preguntar teológico -

\begin{abstract}
The interaction between people from different cultures - affected by global factors and by the change of times - encourages new ways of thinking in Latin America. In dialoguing with philosophical voices (and especially with Raul Fornet-Betancourt), you can see ways of understanding and transforming the world; this dialogue raises theological questions. After noting contextual elements, I consider some axes of intercultural thinking, and through them I outline five types of questions. In my opinion, sciences do not explain problems that are solved by Christian parameters. Rather, a
\end{abstract}

1 Chileno. Licenciado en Teología por la Pontificia Universidad Católica de Chile, 1969. Master of Arts, Religious Studies en la Divinity School, University of Chicago, 1975. Académico de la Universidad Católica Silva Henríquez de Santiago de Chile diegir06@gmail.com 
fruitful and symmetrical polylogue allows to take steps towards a liberating humanization. Questions are faced reconfiguring the Christian imaginary.

Keywords: Intercultural and interreligious - Fornet Betancourt - Theological question

\section{Resumo}

A interação entre pessoas de diferentes culturas afetadas por fatores globais e a mudança de tempo- incentiva novas formas de pensar na América Latina. Ao dialogar com vozes filosóficas (especialmente com Raul Fornet-Betancourt), veem-se maneiras de entender e transformar o mundo; este diálogo levanta questões teológicas. Depois de marcar elementos contextuais, considero alguns eixos do pensamento intercultural, e graças a eles eu vou delineando cinco tipos de interrogantes. Em minha opinião, as ciências não explicam problemas que sejam resolvidos por meio de parâmetros cristãos. Mais bem, um polígono fecundo e simétrico permite dar passos a uma humanização libertadora. Neste caminhar são enfrentadas as perguntas que reconfiguram o imaginário cristão.

Palavras-chave: O intercultural e inter-religioso - Fornet Betancourt Perguntar teológico

La demanda por lo cultural aquí en Chile (y en el continente) conlleva interactuar entre realidades diferentes. Preocuparse sólo de íconos nacionales conlleva enclaustramiento. De hecho cada persona y sector de la población siente, piensa y actúa interculturalmente. Esto no sólo afecta radicalmente a las ciencias; ello también agita la reflexión creyente (que lamentablemente a menudo ha sido unidimensional).

Estas temáticas suelen ser abordadas con ingenuidad. Las culturas son vistas como si fueran segmentos de la realidad, a las que se aplica un análisis social y/o una mirada de fe. También sería ingenuo tratar culturas como si fueran esencias (en el terreno de las identidades o de los objetos). También uno pierde el tiempo si considera entidades estáticas. Es imposible autoafirmarse desconectado de quienes son diferentes. Más bien hay que abordar la complejidad de procesos humanos, que nos desinstalan. Son procesos que requieren diversas lecturas, y que ofrecen una gama de vías de acción.

Para superar hábitos simplistas y lecturas unilaterales, valen las actitudes cuestionadoras. Vale decir, vale un aproximarse a la realidad mediante preguntas fundantes, en vez de que todo gire en torno a 
hipótesis a verificar, apologías de tesis, y argumentos conceptuales. Al respecto, la literatura ofrece grandes recursos. Por ejemplo, Pablo Neruda y sus acuciantes interrogantes:

\author{
"Las hojas viven en invierno en secreto con las raíces? \\ Qué aprendió el árbol de la tierra para conversar con el \\ cielo? \\ (...) cómo saben las raíces que deben subir a la luz, \\ y luego saludar al aire con tantas flores y colores?"2
}

Cada preguntar fundante nos abre ojos y oídos, corazones y mentes, para involucrarse a fondo en un itinerario reflexivo. Esto es constatado en la poesía, en la filosofía, en la teología.

En cuanto al pensar creyente, no vale presuponer 'objetos' culturales que uno examinaría, y menos aún ubicarse aparte o por encima de varios modos de ser. En general, el pensar es interpelado por sensibilidades humanas, sujetos históricos, procesos culturales. Ante realidades fascinantes, $y$ tantas veces perturbadoras, uno puede cerrar ojos y oídos y sólo dedicarse a una especialidad; o uno puede optar por el desafiante diálogo que elucida interrogantes sobre el presente y el porvenir ${ }^{3}$.

\footnotetext{
2 Pablo Neruda, Libro de las Preguntas, Buenos Aires: Losada, 1975, 55, 94-95 (anoto fragmentos de las preguntas XLI y LXXII).

3 Cuando uno aborda una temática suele hacerlo desde una perspectiva; un gran desafío es involucrarse con otros modos de pensar. Al abordar lo intercultural me siento deudor de muchos trabajos, y en especial de hermenéuticas socio-históricas. simbólicas, económico-culturales. En años recientes me impactan (nombrando sólo a pocos y disculpándome de otros) Néstor García Canclini, Martín Hopenhayn, Sonia Montecino, Daniel Martuccelli, Cristián Parker, Bernardo Guerrero, Jorge Larraín, Eugenio Tironi, Xavier Albó, José Bengoa, Alberto Mayol, Daniel Cabrera; y en terrenos de la filosofía y la teología: Antonieta Potente, Leonardo Boff, Franz Hinkelammert, Juan Carlos Scannone, Antonio Bentué, Humberto Giannini, Ricardo Salas, José Estermann, Domingo Llanque, Pedro Trigo, Paulo Suess, Maximiliano Salinas, Alberto da Silva Moreira, Faustino Teixeira. Con éstas y otras personas voy incursionando en varias temáticas; les agradezco de todo corazón. Ojalá sea posible un constante intercambio entre quienes somos huéspedes de pueblos que conjugan culturas y que generan polifacéticos proyectos históricos y caminos espirituales.
} 
La interacción entre personas de diferentes culturas -afectadas por factores globales y por el cambio de época- incentiva nuevos modos de pensar en América Latina. Por ejemplo, uno puede considerar trayectorias históricas y sabidurías creyentes de poblaciones andinas, con creencias y ritos de carácter intercultural e interreligioso, con la conjugación de lo originario y lo mestizo, y con modos de seleccionar lo que viene de otras latitudes ${ }^{4}$.

Ahora bien, la labor intercultural ofrece grandes interrogantes: ¿cómo las trayectorias humanas afectan las doctrinas cristianas? ¿Cómo los plurales caminos socio-espirituales manifiestan imágenes, rostros de Dios? ¿Cómo es releído el Evangelio vivido entre culturas y entre religiones? ¿Cómo interculturalmente comprender a Cristo y al Espíritu de Vida? ¿Cómo es entendida la revelación de Dios, en medio de un cambio de época?

\section{1) Trayectorias actuales}

Ante un complejo escenario mundial, regional, local, con inéditos desafíos y donde hay hegemonías monoculturales, algunas personas e instituciones retomamos el lenguaje intercultural y utópico. Tomando en cuenta estos procesos globales y locales, y en especial la propuesta intercultural, ¿qué palabra teológica es relevante? ¿Con qué perspectiva evangélica encaramos diversos universos simbólicos? A mi parecer, en el actual acontecer humano, por un lado la actitud creyente es realista y a la vez dialoga con utopías (como la altermundista, como la eco-humana), y cabe por otro lado éticamente confrontar la sacralizada globalización neoliberal. Todo esto parece imposible. Sin embargo, en lugares del continente hay grupos y redes cristianas que dan pasos realistas hacia adelante.

La mística cristiana no es atemporal; más bien ella sintoniza con el Verbo encarnado; y así la reflexión camina con los pies bien situados en

429 años en el Perú (y el transitar por otros espacios) me motivan a pensar entre culturas y modos de creer. 
la tierra y en las culturas donde el Verbo se ha encarnado. Si la reflexión es terrenal, no habrá dicotomías, ni un poner a Dios a favor de unos y distante o ausente de otros. Al respecto, Pedro Casaldáliga anota semillas del Verbo esparcidas en cada cultura y pueblo, y advierte: "si en este particular no tenemos las ideas claras, acabaremos pensando en dos dioses ... para unos seres humanos Dios sería plenamente salvador... y para con la otra inmensa mayoría de la humanidad sería mas o menos bueno permitiéndole unas migajas" ${ }^{5}$. Tal imaginario es discriminatorio. Más bien, al acoger la revelación divina es posible en cada cultura ver a Dios presente, y reconocible, y dando frutos. También en la interacción entre culturas sobreabundan las semillas y frutos del Verbo encarnado. A lo largo de este ensayo se presupone el potencial intercultural de vivencias cristianas (lo que conlleva validez de varios tipos de reflexión creyente).

Pues bien, al dialogar con voces filosóficas, uno constata modos de entender y transformar el mundo. Además, tal diálogo suscita interrogantes teológicos ( $\mathrm{y}$ a esto dedico las páginas que usted tiene en sus manos). Por un tiempo nos acostumbraron a presuponer que el ser humano formula preguntas y que el pensar creyente da respuestas; lo que ubica a la teología por encima y como supervisora de la labor humana. Sería una postura soberbia e inviable. Al tratar con modestia estos asuntos, y al retomar el mensaje evangélico, es admirable el rol que juega la capacidad de preguntar ${ }^{6}$. Es un cambio de rumbo con respecto al diálogo con las ciencias. Ellas incentivan a la teología a desenvolver su potencialidad intercultural. Hace unas décadas la antropología pastoral motivó a personas a pensar la fe en términos de

5 Dom Pedro Casaldaliga, El vuelo del Quetzal, Managua, 1988 (en www.servicioskoinonia.org).

6 Véase Fernando Montes, Las preguntas de Jesús, Santiago: Tiberíades, 2002. Desde hace unos años estoy rastreando el preguntar en textos del Evangelio. Por ejemplo, en el Evangelio de Marcos Ilaman la atención los siguientes textos: 2,8, 2,19, 2,25, $3,4,3,22,3,33,4,13,4,21,4,30,4,40,5,9,5,30,5,39,6,38,7,18-19,8,12,8,17-21$, $8,23,8,27,29,8,36-37,9,12,9,16,9,19,9,21,9,33,9,50,10,3,10,18,10,36,38$, $10,51,11,17,11,30,12,10,12,15,12,16,12,24,26,12,35-37,13,2,14,6,14,14$, $14,37,14,49,15,34$. 
inculturación; asimismo en estos últimos años las ciencias humanas abren las ventanas a lo intercultural e interreligioso.

A continuación, motivado por luces y conceptos latinoamericanos y europeos, voy delineando inquietudes y preguntas de carácter teológico ${ }^{7}$. Al dialogar con Raúl Fornet doy un parecer provisional, en un terreno que está en manos de cada persona y donde caben todos los puntos de vista. El mío es limitado y lleno de interrogantes.

Ahora bien, ¿cuáles serían cuestiones de fondo? Creo que el mundo contemporáneo exige lecturas que no sean unidisciplinares ni que pongan piedras a un caminar emancipador. En la renovación posconciliar y en especial en la década actual hay buenas señales de búsqueda de la verdad. Pero lo intercultural aún está en pañales. ¿Existen energías metodológicas para conjugar lecturas provenientes de diversas trayectorias culturales? Lo intercultural e interreligioso, ¿puede ser, no algo añadido a una lista de temas, sino más bien unos componentes en cada paso del caminar reflexivo?

Coincido con el amigo y maestro Fornet que el mayor desafío es la constante trasformación intercultural e interreligiosa de la labor teológica. Ella busca ser fiel al Espíritu y a la realidad que llamamos Dios. Como anota Fornet: el desarrollo del quehacer teológico intercultural e interreligioso "es una exigencia de la profunda y inagotable diversidad del Espíritu", "porque la realidad que confesamos con el nombre Dios se da ella misma en muchos nombres" ${ }^{\prime \prime}$. No se habla pues de lo

7 Siendo vastísima la obra de Fornet, mi ensayo se limita a Interculturalidad y religión, para una lectura intercultural de la crisis actual del cristianismo (Quito: Abya Yala, 2007), y "El quehacer teológico en el contexto del diálogo entre las culturas en América Latina" (manuscrito, 2006). También véase Filosofía Intercultural (México: Universidad Pontificia, 1994), Interculturalidad y globalización, ejercicios de crítica filosófica intercultural en el contexto de la globalización neoliberal (San José, Frankfurt: DEI/ICO, 2000), Transformación intercultural de la filosofía (Bilbao: Descleé, 2001), "De la inculturación a la interculturalidad", Interculturalidad, diálogo interreligioso y liberación, JJ Tamayo, R. Fornet-Betancourt eds., (Estella, Verbo Divino, 2005, pgs. 43-60).

8 "El quehacer teológico en el contexto del diálogo..." (manuscrito que me facilitó el autor, 2006). 
transcendente en forma unilateral ni con categorías absolutas. Más bien el lenguaje teológico es polisémico y polifónico.

Aquí nos encontramos no sólo con condicionamientos intrateológicos sino también con signos de nuestros tiempos que desinstalan. En los actuales contextos de globalización y de cambio de época, se aceleran los encuentros y desencuentros entre pueblos. Hay oleadas de migración en todo el planeta, y amplias ofertas de sentido. Emergen identidades complejas, y crecen los contactos y también aumentan las distancias debido a la comunicación electrónica y computarizada. Estos factores motivan a la labor teológica a reubicarse en la interacción entre culturas y entre religiones, entre diferentes sabidurías y sensibilidades.

Al revisar una de las numerosas obras de R. Fornet ${ }^{9}$ tomo nota de dos acentos. Un acento es diagnosticar una crisis integral, en el contexto global y neoliberal donde predomina la cultura de Occidente; $y$ allí es criticado el modelo inculturador. Opino que la problemática mayor es que el mercado mundial condiciona la interacción entre culturas. Un indicador es la producción denominada folklórica, que se rige por parámetros no del arte ni de necesidades de sus gestores, sino por pautas del mercado planetario.

Un segundo acento. Se propone pasar de la monocultura a lo intercultural, ya sea en la propuesta filosófica (Fornet 1994, 2001) como en los contactos con otras culturas (Sauquet, Vielajus 2014). Confrontar el dominio y postular la convivencia plural y solidaria entre diferentes. Pasar de la globalización neoliberal que uniformiza a una transformación de relaciones donde entidades diferentes se acercan (y se alejan). Al respecto, veo que lo monocultural corresponde a grupos de poder existentes en el Norte y el Sur del planeta; y que lo genuinamente intercultural proviene de la praxis y espiritualidad de pueblos marginados que aceptan a otros e interactúan simétricamente con gente diferente.

9 Me refiero a Interculturalidad y religión, para una lectura intercultural de la crisis actual del cristianismo (Quito: Abya Yala, 2007, y en especial págs. 51-112). 


\section{2) Líneas de filosofía intercultural}

Con respecto al presente y porvenir del factor cristiano, ya que no estamos en situación de cristiandad, es ineludible asumir retos de la pluralidad latinoamericana. R. Fornet confronta al sujeto occidental que pretende tener un punto de vista absoluto, y habla de lo transcendente en sentido absoluto. En nuestro continente las élites ponen sus intereses y lógicas por encima de los demás. También cabe cuestionar el modelo monocultural cristiano que desestructura ritual y simbólicamente a pueblos autóctonos. Es pues ineludible un honesto cuestionamiento intracristiano, y es evidentemente necesario pasar de lo monocultural a lo intercultural. Por otra parte, en la medida que el cristianismo es plural y policéntrico, puede manifestarse la universalidad de la fe cristiana. En cuanto al porvenir cristiano (a mi juicio) lo importante no es la pervivencia de instituciones religiosas, sino una vida digna que conlleva (en sentido creyente) la fidelidad a Dios, que nos motiva a desafiliarnos de idolatrías presentes en el mercado globalizado.

La crítica hecha por Fornet al modelo hegemónico puede ir acompañada por el aprecio a tanto cristianismo inculturado en pequeños y medianos ámbitos de América Latina. Así lo demuestra la población andina (y algo similar es manifestado en espacios mestizos urbanos y en diversas culturas). Deseo pues reivindicar el pasado y presente de procesos de inculturación gracias a poblaciones generadoras de sus formas de fe, gracias a la creatividad de pueblos indoafroamericanos. Esto apunta hacia un buen porvenir de pueblos donde hay diferencias, y éstas pueden ser conjugadas a favor de la Vida.

Un segundo tema controversial es si cabe apartarse de la inculturación, y más bien dedicarse a lo intercultural. Aquella lamentablemente ha sido entendida como una intervención asimétrica, en que agentes cristianos inculcan el mensaje evangélico en las culturas. En muchos modos se ha desenvuelto una misión colonizando al diferente. Resulta pues siendo una acción violenta; las culturas indoafroamericanas son evaluadas por un tribunal cristiano. Otro gran error ha sido inculturar sin inreligionar, sin un fecundo intercambio entre lo cristiano y otros 
modos de creer. De hecho en la extensa historia cristiana ella ha asumido rasgos religiosos en diversos momentos y lugares del mundo. La verdad es que suele ser fácil respetar valores culturales, y suele ser cuestionador convivir con otras religiones (sin devaluarlas) y apreciar espiritualidades sincréticas del pueblo.

Ante la neocristiandad colonizadora, y en la medida que es asumida una perspectiva intercultural, cabe la dimisión (y no la misión colonizadora); al respecto vale la exigente lista de renuncias indicadas por nuestro maestro (Fornet 2005 57-60). No hay cambio sin renuncia, sin conversión. Puede añadirse que algo se va logrando en vivencias inculturadas e inreligionadas de la fe cristiana, que abundan en la cotidianeidad del pobre ${ }^{10}$. También es deseable que inculturaciones hechas por comunidades cristianas de base vayan de la mano con vivencias de fe realizadas entre culturas; es un desafío encarado, por ejemplo, en los bianuales encuentros intereclesiales en el Brasil' ${ }^{11}$.

Otra gran temática es la crisis de la religión cristiana que predomina en Occidente. Fornet argumenta que tal crisis religiosa y eclesial puede ubicarse dentro de una crisis del mundo, de la razón, de la subjetividad. Esto es más palpable en regiones noratlánticas y en tantas zonas del mundo parametradas por aquellas. Por otra parte, para sectores significativos (y hasta para muchedumbres) en el Sur y también en el Norte, la religión es fuerza para resolver cuestiones concretas y para sostener grados de esperanza. En la tradición atenta a la obra de José Martí, se plantea la religión como anhelo de crecimiento espiritual necesario a pueblos para no morir. Pues bien, la interculturalidad conlleva diálogo con espiritualidades y con religiosidades.

\footnotetext{
10 Esto sobresale en mundos festivos; véase uno de mis trabajos en el Perú, La fiesta, símbolo de libertad (Lima: CEP, 1998), y geniales obras de Maximiliano Salinas, Gracias a Dios que comí (México: Dabar, 2000), Lo que puede el sentimiento, El amor en las culturas indígenas y mestizas en Chile y América del Sur, siglos XIX y XX (Santiago: Ocho Libros, 2015).

11 Véase Faustino Teixeira, Os encontros intereclesiais de CEBs no Brasil, Sao Paulo: Paulinas, 1996; Clodovis. Boff, As comunidades de base em questao, Sao Paulo: Paulinas, 1997.
} 
Por otra parte, existen vías sin salidas, o con obstáculos para la convivencia. Fornet anota problemáticas como el sincretismo esotérico, la parasicología, la postura gnóstica. Nuestro maestro no adhiere a la vieja enemistad entre filosofía y religión, ni a una visión hegeliana según la cual la morada de la religión cristiana sería la razón moderna. Sin embargo, algo de eso es manifestado por el pensar cristiano hegemónico, ya que toma distancia y hasta es adversario de religiones del pueblo; es un pensar subordinado a lógicas de las élites.

Una cuestión más de fondo es que persisten alternativas y acciones de liberación con rasgos interculturales e interreligiosos. R. Fornet recalca que el pensar filosófico y teológico hoy en América Latina es liberador y/o intercultural. La labor entre culturas puede implicar alternativas a la globalización neo liberal; puede conllevar proyectos de convivencia y solidaridad entre mundos diferentes. De modo filosófico cabe anotar que las tradiciones religiosas son punto de partida para abrirse a Dios. En cuanto a la convergencia y divergencia (entre liberación e interculturalidad) cabe continuar con este buen debate. Se trata de lenguajes no esencialistas, sino más bien con carácter dinámico y pluridimensional.

\section{3) Indagaciones teológicas}

Al estar envuelto en tanto tema fascinante, rebrotan muchas inquietudes. A continuación presento cinco líneas de interrogantes ${ }^{12}$. El aporte científico y sapiencial conmueve e interpela la labor teológica. La cuestión básica es si lo intercultural e interreligioso está modificando nuestros modos de pensar la fe. En situaciones pluralistas, ¿cómo se entiende la universalidad del Logos y del Pneuma? En medio de una crisis sistémica y de un cambio de época, ¿qué rasgos de la revelación de Dios son más relevantes? Sólo voy a delinear interrogantes, ya que

12 Estos cinco tipos son explicados de modo similar en mi texto "Interculturalidad y preguntar teológico" (2016, inédito). 
empezar a responderlos es labor de largo plazo y conviene hacerlo de manera interdisciplinaria.

Primera línea de interrogantes. En América Latina y otras regiones del mundo, las teologías han comenzado a considerar lo socio-económico, identidades, culturas, religiones, la ecología, la perspectiva de género. En este escenario pluridimensional se intenta comprender realidades donde ocurre la salvación en Cristo, y poder aproximarse al misterio del Dios-Amor. A mi modo de ver no se trata de reflexionar en genitivo (teología de lo cultural, lo económico, etc.), sino de pensar en forma interactiva. Existen modos de entender tales realidades, con hermenéuticas propias; ello incentiva el preguntar teológico, como ver el sentido de la fe en Dios que ocurre entre pueblos diferentes.

Esto implica que el procedimiento es, ya no el de preguntas humanas y respuestas teológicas, sino ahora es un preguntar y un responder tanto desde las ciencias como desde la reflexión creyente. Por ejemplo, vale preguntar cómo el creer en el Dios de la Vida va de la mano con el no creer en ídolos del mercado, siendo esta segunda parte tan teológica como la primera. Esta reflexión es hecha, a veces, por estudiosos de la doctrina social, aunque mayormente es hecha por personas sabias que impugnan la sacralizada economía contemporánea.

Pues bien, tal como en la organización material y espiritual de la condición humana, también en otros terrenos cabe hacer preguntas. Sujetos y temáticas humanas ingresan al interior de la actividad teológica. No son sólo asuntos tangenciales.

Segunda línea de interrogantes. A lo largo de estas páginas la mayor inquietud es: ¿lo intercultural e interreligioso de hecho está transformando la teología latinoamericana? Esto implica no encasillar culturas y religiones, sino más bien sopesar procesos históricos en medio de los cuales la comunidad cree y ama. Se requiere además que lo intercultural no sea un objeto de estudio, sino que motive modos de pensar entre comunidades humanas (que algunos llaman: polílogo). Ya que cada polílogo suele ocurrir en contextos asimétricos, hay que proceder de modo crítico a fin de caminar hacia la simetría entre pueblos, entre culturas. En lo intercultural las voces cristianas 
no pueden sobreponerse a otras formas de sentir y pensar; por eso cada comunidad tiene que llevar a cabo su itinerario de aprendizaje, de escuchar y de hablar polifónico. En cuanto a los principios de la fe, que responden a la revelación bíblica, no pueden encerrarse en tal o cual cultura. La Buena Nueva del Verbo encarnado es relevante a cada persona y sector humano que busca plenitud de vida.

Aun más complicado, para quienes confesamos a Jesucristo como Salvador, es tomar en serio el desafío interreligioso. Nos acostumbraron a pensar que la fe (don divino) sobrepasa la religión (producto humano). Pero la historia muestra que la fe evangélica, presente en diversas épocas y procesos simbólicos, se ha in-religionado. Además, cada elaboración teológica esta sobrecargada de creencias y ritos que nos ponen en contacto con otros mundos. También hay que considerar si hoy los plurales caminos espirituales de la humanidad (incluyendo formas posmodernas) están manifestando 'rostros' de Dios.

Ahora bien, ¿con qué metodología intercultural e interreligiosa es desarrollada la reflexión cristiana y cada temática teológica? La salvación, ¿cómo es universal y particular? Además, gracias a opciones latinoamericanas, la reflexión de la fe es llevada a cabo desde y con los pobres; esto conlleva, desde y con sus caminos espirituales. Aquí brotan grandes preguntas.

Tercera línea de interrogantes. Otro gran desafío es pensar hoy interculturalmente la fe cristiana nutrida por sus raíces evangélicas. En este continente, catalogado como mayormente creyente, y en parte regido por la iglesia católica, se entrecruzan diversas búsquedas de plenitud humana y espiritual. Por eso es releída la Buena Nueva en ambientes plurales y ecuménicos, y también la lectura ocurre en ambientes secularizados que de varios modos reconstruyen lo espiritual.

Estas actividades no parten de cero. Durante las últimas décadas, la fidelidad al Evangelio ha sido la fuente de las más importantes elaboraciones teológicas (por su profundidad y por sus millares de protagonistas en comunidades de base y en programas de estudio bíblico). No sólo lo teológico ha estado preocupado con la injusticia social y con iniciativas de cambio histórico. Principalmente la reflexión se ha 
reconectado con el Jesús del Evangelio, con su Espíritu en la historia (que incluye confrontar las causas de la deshumanización social). En ese sentido el mayor trabajo hacia adelante es una cristología bíblica con rasgos interculturales e interreligiosos.

Esto implica una tarea intensa. Se han consolidado ensayos de hermenéuticas específicas, por parte de comunidades urbano-marginales, indígenas, afroamericanas, campesinas, y por parte de la mujer, del joven, del migrante, de excluidos y de nuevos protagonistas. Pues bien, para gran parte de la polifacética población latinoamericana la relectura intercultural y comunitaria del Evangelio es tarea por realizar. La humanidad anhela una Buena Nueva que no sea sectaria ni intrarreligiosa. Por ejemplo, son relevantes las interacciones de Jesús con la cananea del pan que comen los perritos, con los centuriones y las samaritanas en nuestras ciudades. La praxis creyente se vuelca al mensaje del Reino, al banquete para todo pobre y donde entra gente de Oriente y Occidente.

Cuarta línea de interrogantes. También surge la pregunta sobre significados del Verbo y del Pneuma en sintonía con diversas condiciones humanas, sabidurías, espiritualidades latinoamericanas. Siendo universal el amor de Dios, hay que impugnar cualquier apropiación sectaria del Verbo encarnado, y hay que encarar sectores carismáticos y organismos oficiales que intentan adueñarse del Espíritu. La Ruah, el Pneuma, vivifican todos los carismas humanos. Ni Cristo ni su Espíritu tienen fronteras, ni sustentan fanatismos. Sin embargo, existe mucha absolutización con ropaje cristiano. Duele mucho constatar tanta intolerancia e insolidaridad entre culturas y religiones. Por eso, vale reafirmar la universalidad del Verbo y del Pneuma de Dios revelado por Jesucristo. La fe conlleva una sintonía y praxis intercultural e interreligiosa; ello desestabiliza esquemas autocentrados.

En los años venideros es probable que los interrogantes sobre la cristología y pneumatología latinoamericana tengan rasgos interactivos y policéntricos. Como Jesucristo es sacramento del amor universal de Dios dirigido a cada persona y comunidad, ¿cómo será entendido el universalismo del Verbo entre diversos espacios y tiempos humanos? 
Ya que el Espíritu cristiano se mueve con libertad entre culturas y entre religiones ( $y$ entre increencias, entre sincretismos), ¿cómo pueden apreciarse las maravillas de Dios que habla polifónicamente a diversos pueblos y trayectorias humanas? Esto no quiere decir diluir la fe cristiana, ni relativizarla, ya que su relevancia e interpelación es universal.

Quinta línea de interrogantes. Otra gran preocupación se refiere al porvenir que ya ha comenzado. Al encontrarnos en medio de una crisis civilizatoria y un cambio axial, ¿cómo es escuchado y puesto en práctica el Evangelio de la liberación sin fronteras? En comunidades que asumen su pluralidad, ¿qué imágenes de Dios se van revelando? El misterio ¿es entendido como desacralizador, y como fuerza que impugna ídolos tradicionales e ídolos modernos? Hoy parece prioritario desacralizar un mercado-cultura que es unidimensional, y que suscita sectarismo y alienación.

A veces uno es contagiado por estadísticas optimistas en la producción de bienes masivos y en la innovación tecnológica. Al respecto vale escuchar voces cautas y previsoras. El progreso a nivel mundial tiene el lado oscuro de la infelicidad. Mientras uno consume más, también aumenta el vacío de relaciones y de transcendencia. Por otra parte, con fuerza hoy resurge la espiritualidad y praxis del Evangelio del amor de Dios. Este resurgimiento puede purificar espacios religiosos y eclesiales.

Voy concluyendo. Puede decirse que se manifiesta el Verbo de Dios encarnado en la polifonía humana a través de la humanidad pobre. Puede añadirse que está presente la Ruah y la Sabiduría de Dios; ellas suscitan carismas de diálogo a favor de la vida, sanación integral, profecía dentro y más allá de las religiones, liderazgo servicial, redes solidarias. De varias maneras, personas en el mundo de hoy desean un liberador y polifónico pensar la fe. Se aprecia la honestidad y el coraje al hacernos preguntas de fondo. Para ello ayudan muchísimo unas metodologías de caracter intercultural e interreligioso. De varias maneras la humanidad va confrontando la maldad y va reconociendo el regalo del amor divino. Al dialogar entre formas de fe (y con formas de increencia) es posible acercarse, en silencio, al incondicional regalo de Vivir. 


\section{Bibliografía}

Albó, Xavier. Iguales aunque diferentes, hacia unas políticas interculturales y lingüísticas para Bolivia. La Paz: CIPCA, 2002.

Boff, Clodovis. As comunidades de base em questao. Sao Paulo: Paulinas, 1997.

Casaldáliga, Pedro. El vuelo del Quetzal. Managua, 1988 (www.servicioskoinonia.org)

Fornet-Betancourt, Raúl. Filosofía Intercultural. México: Universidad Pontificia Mexicana, 1994.

Fornet-Betancourt, Raúl. Interculturalidad y globalización. San José, Frankfurt: $\mathrm{DEI} / \mathrm{ICO}, 2000$.

Fornet-Betancourt, Raúl. Transformación intercultural de la filosofía. Bilbao: Desclee, 2001.

Fornet-Betancourt, Raúl. "De la inculturación a la interculturalidad". Interculturalidad, diálogo interreligioso y liberación. Ed. Juan José Tamayo, R. Fornet. Estella: Verbo Divino, 2005: 43-60.

Fornet-Betancourt, Raúl. "El quehacer teológico en el contexto del diálogo entre las culturas en América Latina" (manuscrito, 2006).

Fornet-Betancourt, Raúl. Interculturalidad y religión, para una lectura intercultural de la crisis actual del cristianismo. Quito: Abya Yala, 2007.

García Canclini, Néstor. Diferentes, desiguales y desconectados, Mapas de la interculturalidad. Barcelona: Gedisa, 2004.

Irarrazaval, Diego. La fiesta, símbolo de libertad. Lima: CEP, 1998.

Irarrazaval, Diego. Itinerarios en la fe andina. Cochabamba: Verbo Divino, 2013.

Montes, Fernando. Las preguntas de Jesús. Santiago: Tiberíades, 2002.

Morin, Edgar; Le Moigne, Jean Louis. A inteligencia da complexidade. Sao Paulo: Petrópolis, 2000.

Neruda, Pablo. Libro de las Preguntas. Buenos Aires: Losada, 1975.

Salas, Ricardo; Álvarez, David (eds.). Estudios interculturales, hermenéutica y sujetos históricos. Santiago: UCSH, 2006.

Salinas, Maximiliano. Gracias a Dios que comí. México: Dabar, 2000.

Salinas, Maximiliano. Lo que puede el sentimiento, El amor en las culturas indígenas y mestizas en Chile y América del Sur, siglos XIX y XX. Santiago: Ocho Libros, 2015. 
Sauquat, Michel; Vielajus, Martin. L'intelligence interculturelle. 15 themes a explorer pour travailler au contact d'autres cultures, Paris: C.L. Mayer, 2014.

Teixeira, Faustino. Os encontros intereclesiais de CEBs no Brasil. Sao Paulo: Paulinas, 1996. 